Araştırma ve Geliştirme Dergisi

International Journal of

Engineering Research and

Development
UMAGD, (2021) 13(2), 680-689.

10.29137/umagd.908696

Cilt/Volume:13 Sayı/Issue:2 Haziran/June 2021

Araştırma Makalesi / Research Article

\title{
Mobil Robotların Formasyon Kontrolünde Giriş Kısıtlamaları
}

\section{Input Constraints in Formation Control of Mobile Robots}

\author{
Meral Kılıçarslan Ouach 1 iD, Tolga Eren 1 iD \\ ${ }^{1}$ Kırlkkale Üniversitesi, Mühendislik ve Mimarlık Fakültesi, Elektrik-Elektronik Mühendisliği Bölümü. 71450 Kırıkkale/TÜRKIYYE
}

Başvuru/Received: 03/04/2021

Kabul / Accepted: 04/06/2021

Çevrimiçi Basım / Published Online: 18/06/2021

Son Versiyon/Final Version: 18/06/2021

\section{$\ddot{O} \mathbf{z}$}

Bu çalışmada, Giriş/Çıkış Doğrusallaştırma Tekniği ile, holonomik olmayan mobil robotlara Lider-Takipçi Formasyon Kontrolü uygulandığında, daha iyi sonuçlar veren başlangıç koşulları araştırılmıştır. Başlangıç koşulları bir lider ve iki takipçi robotta denenmiştir. Kontrol kuralı, ilk takipçinin lidere göre istenilen mesafe ve açıyı; ikinci takipçinin lidere göre ve ilk takipçiye göre istenilen mesafeyi koruması şeklindedir. Simülasyonlarda başlangıç koordinatları, hızları ve açılarının değiştirilmesinin robotların tüm lider-takipçi yolculuğunda farklı davranmasına sebep olduğu gözlemlenmiştir. Makalenin sonunda, en iyi takip için optimal başlangıç koşulları önerilmiştir.

\section{Anahtar Kelimeler}

"Robot formasyonu, sürü robotlarl, formasyon kontrolü"

\begin{abstract}
The paper investigates the better possible combined initial conditions of leader-follower formations of nonholonomic mobile robots for Input/Output Linearization Technique. Initial conditions are applied to two followers and one leader robot. The first follower tries to maintain desired distance and angle towards the leader while the second follower tries to maintain desired distances to the first follower and the leader. In simulations, it is observed that, changing initial relative positions and velocities as well as angles can cause robots act differently throughout the whole leader- follower trajectory. At the end, optimum initial conditions are proposed for the best trajectory.
\end{abstract}

Key Words

"Robot formation, swarm robotics, formation control" 


\section{Giriş}

Robot teknolojilerinin gelişmesi, sürü robotlarını gündeme getirdi. Birden fazla robotu aynı anda koordine etmek, takipçilerin lideri izlemesini sağlamak, hepsine ortak bir hedef belirlemek ya da ortakça bir iş üzerinde çalışmalarını sağlamak beraberinde çeşitli kontrol kurallarının da geliştirilmesine yol açtı. Robot formasyon kontrolü ile bir robot grubunun bütünde ve bireysel olarak hareketi gözlemlenir. (Desai vd., 1998, Desai vd., 2001) çalışmasında, holonomik olmayan mobil robotlardan oluşan bir grubun robotların birbirlerine göre istenilen mesafe ve açılarının korunması amacıyla, lider ve takipçiler arasında uzaklık-uzaklık ve uzaklık-açının kontrol edildiği iki farklı geri beslemeli kontrol kuralı geliştirmişlerdir. (X. Wang vd., 2012) çıktı düzenleme bakış açısı ile anahtarlama ara bağlantılı topolojisine sahip kanonik dahili model tabanlı dinamik geri besleme kullanmıştır. Ayrıca lideri olmayan çok robotlu denetleyici mimarili bir grup robotu da kontrol etmek mümkündür. (Meng vd., 2019) modifiye edilmiş doğrusal ikinci dereceden düzenleyici yöntem ile bu tür bir robot grubu için rehberlik ve kontrol kuralı tasarlamıştır. (Ma vd., 2021) özdeş olmayan robotlar üzerinde çalışmış ve optimal dinamik formasyon probleminin önerilen olay tetiklemeli mekanizmalarla sadece aralıklı iletişim ile paylaştırılmış bir kontrol yasası ile çözülebileceğini göstermişlerdir.

Robot formasyon kontrolü sadece basit bir düz arazide değil, insansız su jeti yüzey araçları (D. Wang \& Fu, 2019), insansız hava araçları (Gosiewski \& Ambroziak, 2012), uçaklar (Fierro vd., 2001, Giulietti vd., 2000), otonom su altı araçları (Edwards vd., 2004, Skjetne vd., 2002) ve uzay robotları (Hirzinger vd., 1994) gibi birçok alana uygulanabilir.

Robot formasyonu ile, takipçiler bir veya birden fazla lideri takip ettiklerinde tüm formasyonu korumanın yanında diğer bazı problemlere de çözüm bulmaya çalış1ır. Literatürde birçok yazar, engellerden kaçınma (Wen vd., 2018), rijid formasyonu koruma (T Eren vd., 2005, Tolga Eren, 2012), zamanla değişen çıktı oluşumu takibi (Hua vd., 2019), formasyonu bozmaya çalışan etmenler ve bilinmeyen kontrol yönü (Yang \& Fan, 2019), uyumsuz oryantasyona neden olan ölçüm hataları (Li vd., 2019), çarpışmalar (FloresResendiz \& Aranda-Bricaire, 2020) gibi sorunlara çözüm üretmeye çalışışlardır.

Lider robotun önceden tanımlanmış bir yörünge boyunca hareket ettĭgi bir robot grubunda, geri kalan diğer robotlar bir konumdan diğer konuma geçerken mesafelerini ve açılarını ayarlarlar, aynı zamanda liderlerini takip ederler. Formasyon kontrolü çoğunlukla böylesi bir lider-takipçi yaklaşımı ile ilgilenir. Geri besleme denetleyicileri tarafından yapılan formasyon kontrolü her durumda başarılı bir yörünge garanti etmez. Kontrolörlerin değişkenlerinin başlangıç değerleri en uygun şekilde seçilmezse çarpışma veya formasyonun bozulması gibi sorunlar ortaya çıkabilir. Bu çalı̧̧mada, (Desai vd., 1998, Desai vd., 2001)'in geri besleme denetleyicileri ve holonomik olmayan lider-takipçi sisteminin değişkenlerinin farklı başlangıç koşulları altında robot formasyonunun tepkileri araştırıldı. Uzaklıkaçı kontrolü ve uzaklık-uzaklık kontrolü olan geri besleme kontrolörleri (Desai vd., 1998, Desai vd., 2001) tarafindan Giriş/Çıkış Doğrusallaştırması yönteminden türetilmiştir. Bu kontrol sistemi, uygun başlangıç koşulları seçildiğinde iyi çalışır ve hesaplaması kolaydır. Bu başlangıç koşulları, robotların harekete başlamadan önceki koordinatları, başlangıç hızları, başlangıç açısal hızları, başlangıç açıları, liderlere olan mesafeler ve robotların başlangıçtaki birbirine olan yönelimleridir. Bu başlangıç koşullarının alabilebileceği farklı değerlerin birlikte denenmesi ile takipçilerin davranışlarının ve bütünde robot formasyonunun değiştiği gösterilmiştir. Bu başlangıç koşullarının belirli aralıklardaki bazı değerlerinde robotların çarpıştığı veya istenilen robot formasyonunun elde edilemediği gözlemlenmiştir.

$\mathrm{Bu}$ çalışmanın temel katkısı robot formasyonunda her bir robotun başlangıç koşulları söz konusu olduğunda Giriş/Çıkış Doğrusallaştırma Kontrol Yasası için en iyi başlangıç koşullarını tespit etmektir. Bu çalışma robot formasyonu üzerinde çalışan araştırmacılar için doğru başlangıç koşullarının seçilmesine yardımcı olacaktır.

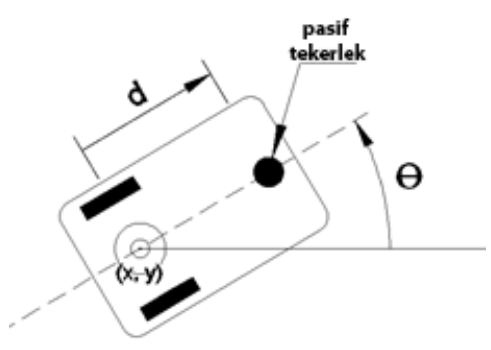

Şekil 1. Basit Bir Mobil Robot ve Değişkenleri (Desai vd., 1998, Desai vd., 2001)

Çalışmanın geri kalanı şu şekilde düzenlenmiştir; 2. Bölüm bazı temel bilgilere ve problemin tanımlanmasına ayrılmıştır. 3. Bölümde simülasyonlara yer verilmiş ve 4 . Bölümde elde edilen bulgular, 5. Bölümde ise bu çalışmanın ana katkısı ve varılan sonuç yer almaktadir. 


\section{Temel Bilgiler ve Problemin Tanımlanması}

Bir robot grubu liderlerini takip ettiklerinde aynı zamanda formasyonu mümkün olan en iyi şekilde sürdürmeye çalışrlar. Takipçi robotlar çeşitli kontrol yasalarından yardım alarak lider robotları takip ederler. (Desai vd., 1998, Desai vd., 2001) çalışmasında formasyon kontrolü için Giriş/Çıkış Doğrusallaştırma Kontrol Yasasını kullanmıştır. Bu kontrol sistemi diğer formasyon kontrolü sistemlerine göre daha yüksek seviyede ama daha düşük karmaşıklıkta ve hesaplanması daha kolaydır. Fakat bu kontrol sisteminin bazı değerlerinin çeşitli başlangıç koşullarında formasyon bozulur veya robotlar birbiri ile çarpışır veya formasyon hiç oluşmaz. Bu çalışmada bu başlangıç koşullarının çeşitli değerlerinde robot grubunun formasyon tepkisi simülasyon yoluyla elde edilmiştir.

Şekil 1'deki gibi, önde pasif bir tekerleği, arkada ise ortak eksenli iki adet tahrikli tekerleği olan her robotun basit bir diferansiyel tahrik konfigürasyonu kullanılarak hareket ettirildiği varsayılır. Bu durumda, bu türdeki robotların denklemleri;

$$
\begin{gathered}
\dot{x}_{i}=v_{i} \cos \theta_{i} \\
\dot{y}_{i}=v_{i} \sin \theta_{i} \\
\dot{\theta}_{i}=\omega_{i}
\end{gathered}
$$

formülleri ile ifade edilir. (1) nolu denklemlerde, alt simge $i$ ile $i$. robot gösterilmiştir. $(x, y, \theta)$; referans noktasına göre robotun arka aksının konumunu $(x, y)$ ve oryantasyonunu $(\theta)$ ifade eder. $\omega_{i}$ açısal hız ve $v_{i}$ arka aksın merkezinin hızıdır. $x$ ve $y$ düzlemlerinde yer değiştirmelerin türevi, çizgisel hız ve robotun $\theta$ açısı ile orantılı; $\theta$ açısının türevi ise açısal hıza eşittir.

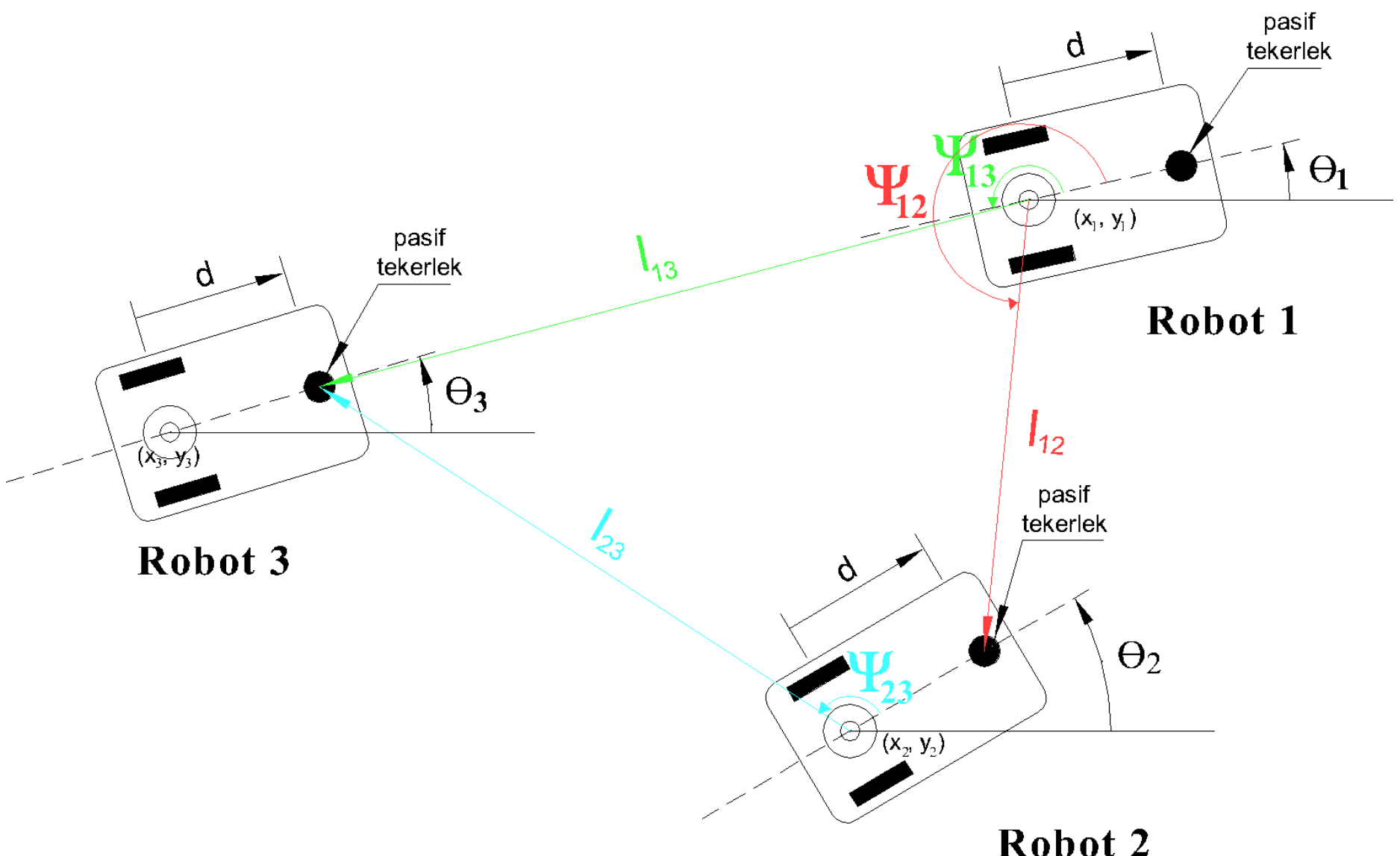

Şekil 2. $l$ - $\Psi$ Kontrol ve $l$ - $l$ Kontrol İçin Gösterim (Desai vd., 1998, Desai vd., 2001) 
Şekil 2'de $l-l$ kontrol ve $l-\Psi$ kontrol kurallarının şematiği gösterilmiştir. Şekilde üç adet özdeş holonomik olmayan mobil robot vardır; Robot 2, $l-\Psi$ kontrol yasasına göre Robot 1'i, Robot 3 de $l-l$ kontrol yasasına göre hem Robot 1'i hem de Robot 2'yi takip etmektedir. Bu kontrolörün amacı, Robot 2'nin Robot 1'e göre olması istenilen açı $\Psi_{12}^{d}$ ve mesafe $l_{12}^{d}$ (Robot 1 lider ve Robot 2 onun takipçisidir) ve Robot 3'ün hem Robot 1 hem de Robot 2'ye göre olması istenilen $l_{13}^{d}$ ve $l_{23}^{d}$ (hem Robot 1 hem de Robot 2, Robot 3'ün lideridir) mesfalerinin korunmasını sağlamaktır. $l_{12}, l_{13}$ ve $l_{23}$ lider robotun arka aksının merkezi ile takipçi robotun ön tekeri arasındaki mesafelerdir. Arkadaki tekerleklerin merkezi ile öndeki pasif tekerleğin arasındaki mesafe $d$ 'dir.

\section{Simülasyonlar}

Simülasyonlarda çeşitli değerlerin farklı başlangıç koşulları denenmiştir, doğrusal ve çembersel takiplerde takipçilerin lideri izleme eğilimleri gözlemlenmiş̧tir. Şekillerde mavi renkteki adım sayıları ile gösterilen robot lider robotu, kırmızı renkteki adım sayıları ile gösterilen robot lider robotu $l-\Psi$ ve $l-l$ kontrol kuralı ile takip eden 2. robotu ve pembe renkteki adım sayıları ile gösterilen robot 2. robotu ve lider robotu $l-l$ kontrol kuralı ile kontrol eden 3. robotu göstermektedir. Robotlar iki boyutlu düzlemde hareket etmişlerdir. $l_{12}, l_{13}$ ve $l_{23}>2 d$ koşulunun olmadığ durumlar için de simülasyonlar yapılmıştır.

\subsection{Başlangıç Konumları}

Bu bölümde robotlar çeşitli koordinatlarda konumlandırılıp robotların hareketleri gözlemlenmiştir. Konumlandırma için robotların orjinleri referans alınmıştır. Robot 1 her zaman $(0,0)$ noktasında konumlanmıştır.

a

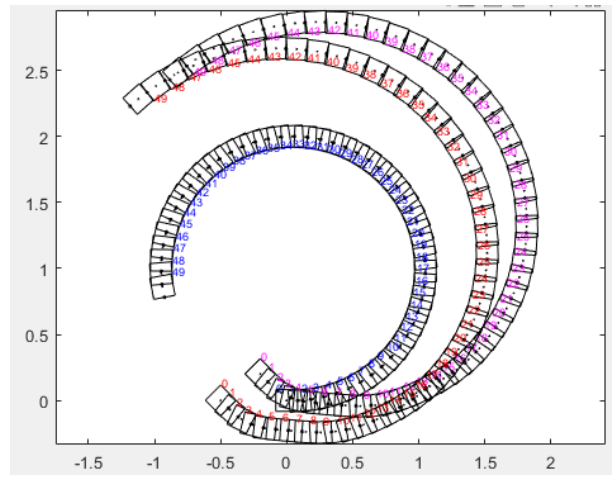

b

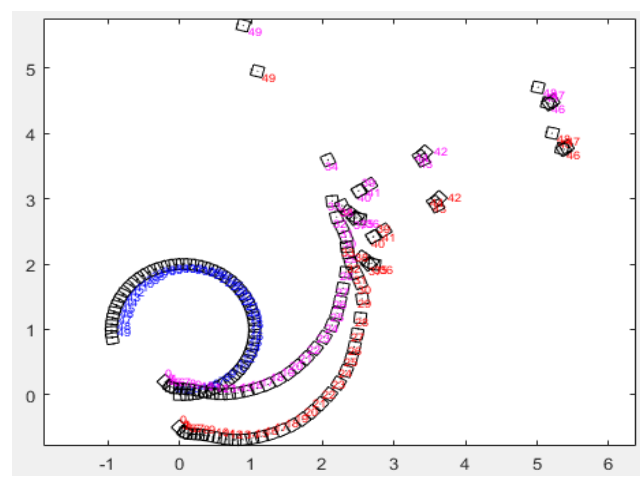

Şekil 3. (a) Liderin En Önde Başlaması; (b) 2. Robotun En Önde Başlaması

Lider Robot harekete en önde başlamadığı durum için gösterilen, izlemenin tam olarak yapılamadığı Şekil 3a'da 2.Robot (-0.5,0), 3 . Robot $(-0.2,0.2)$ noktalarından; b'de 2.Robot $(0,-0.5), 3$. Robot $(-0.2,0.2)$ noktalarından hareketlerine başlamışlardır.

a

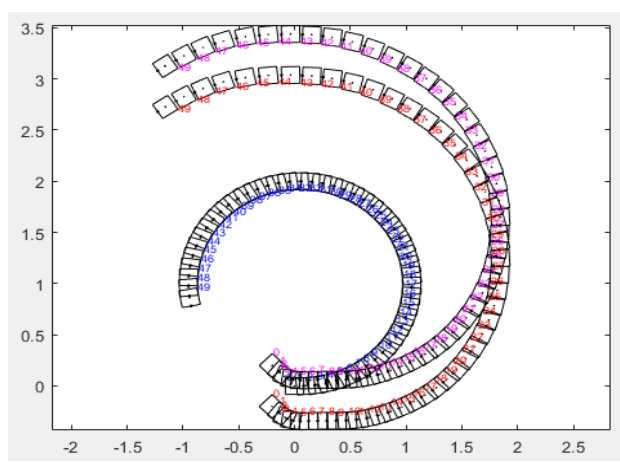

b

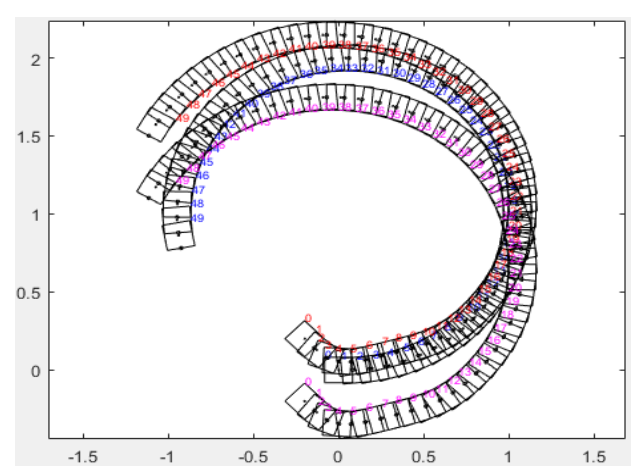

Şekil 4. (a) 3. Robotun Çemberin İçinden, 2. Robotun Çemberin Dışından Başlaması; (b) (a)'daki Durumun Tersi

Harekete 3. Robot çemberin içinden, 2. Robot çemberin dışından başladığı zaman 3. Robot çemberin dışına çıkarak hareketini devam ettiriyor. Tam tersi olduğu durumda; harekete 2. Robot çemberin içinden, 3. Robot çemberin dışından başladığı zaman, bu kez 3. Robot çemberin dışından içeri geçerek hareketini devam ettiriyor. Şekil 4a'da 2.Robot $(-0.2,-0.2), 3$. Robot $(-0.2,0.2)$ noktalarında; b'de 2.Robot (-0.2,-0.2), 3. Robot (-0.2,-0.2) noktalarından hareketlerine başlamışlardır. 
a

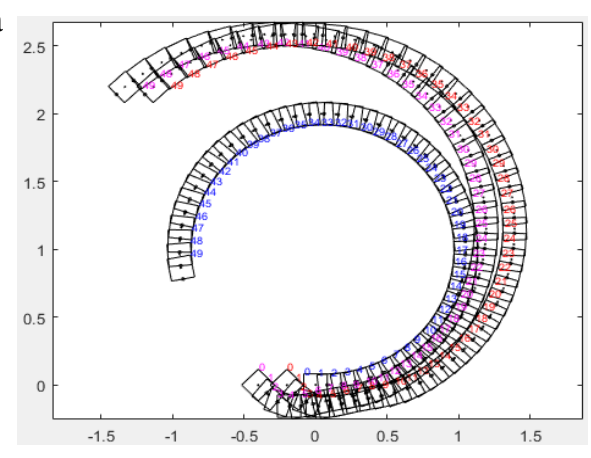

b

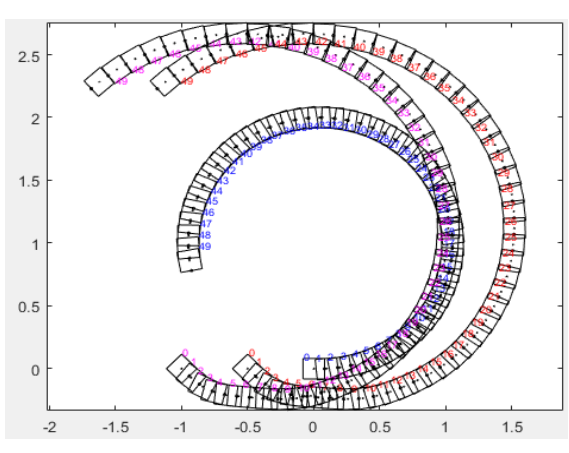

$\mathrm{c}$

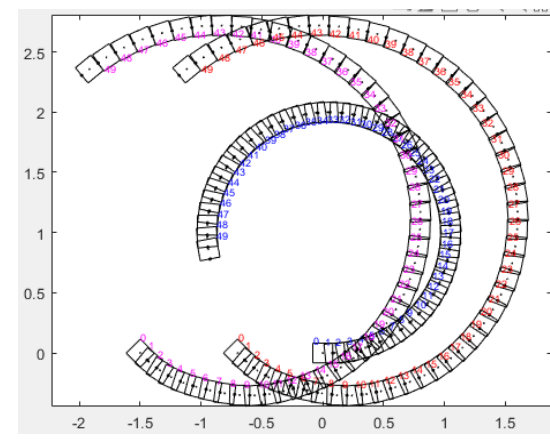

d

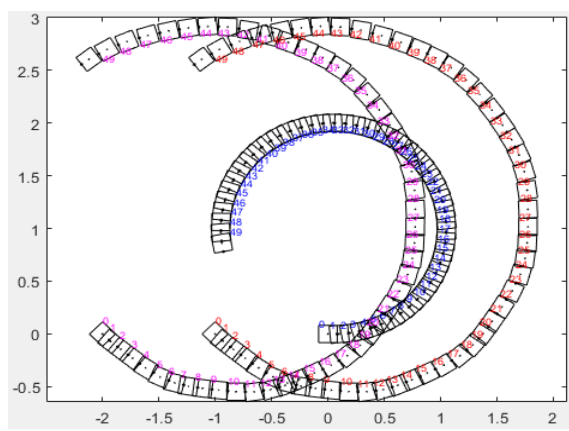

e

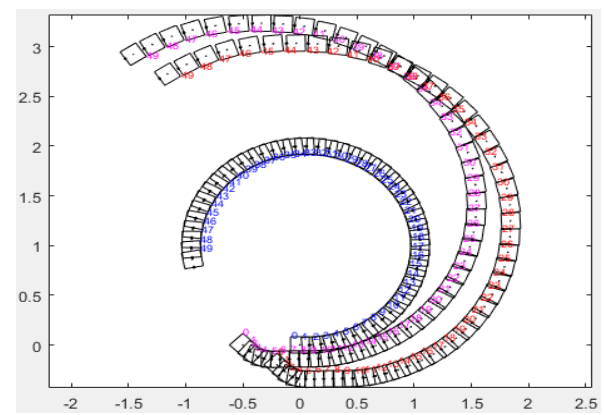

Şekil 5. Üç Robotun Arka Arkaya Sıralanarak Hareketlerine Başlamaları (a) Mesafeler İstenen Uzaklıktan Küçük; (b) Mesafeler İstenen Uzaklıkla Aynı; (c) Mesafeler İstenen Uzaklıktan Büyük; (d) Mesafeler İstenen Uzaklığın İki Katı; (e) Üçüncü Diğer İkisinin de Arkasinda

Harekete, 2. Robot 1.Robotun arkasında, 3.Robot da 2.Robotun arkasında olacak şekilde üç robot da arka arkaya sıralanarak başlarsa, mesafeler istenen uzaklıktan küçük olduğunda çarpışma meydana geliyor, mesafeler istenen uzaklıkla aynı ve istenen uzaklıktan büyük olduğunda çarpışma meydana gelmiyor. Mesafeler istenen uzaklığın iki katı kadar olduğunda izlemeler daha da uzaktan yapılıyor. Eğer 3. Robot diğer ikisini de görecek şekilde arkalarında olursa izleme çok uzaktan yapılıyor. Şekil 5a' da 2.Robot (-0.2,0), 3. Robot (-0.4,0) noktalarında; b'de 2.Robot $(-0.5,0), 3$. Robot $(-1,0)$ noktalarında; c'de 2.Robot $(-0.7,0)$, 3. Robot $(-1.5,0)$ noktalarında; (d)'de 2.Robot $(-1,0), 3$. Robot $(-2,0)$ noktalarında; (e)'de 2. Robot $(-0.2,-0.2)$, 3. Robot $(-0.5,0)$ noktalarından hareketlerine başlamışlardır.

\subsection{Bașlangıç Hızları}

Bu bölümde robotların harekete çeşitli hızlarla başlayıp devamında verdiği tepkiler gözlemlenmiştir.

a

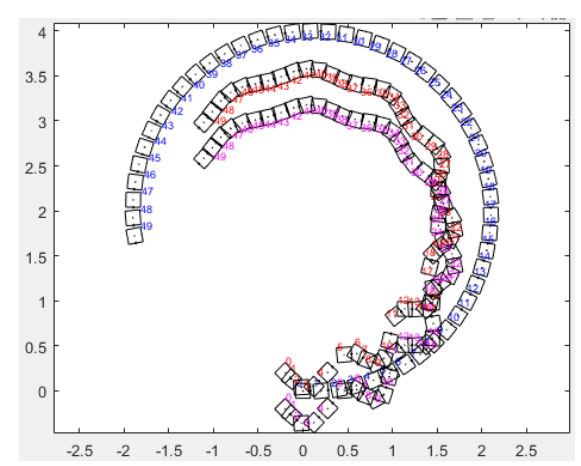

b

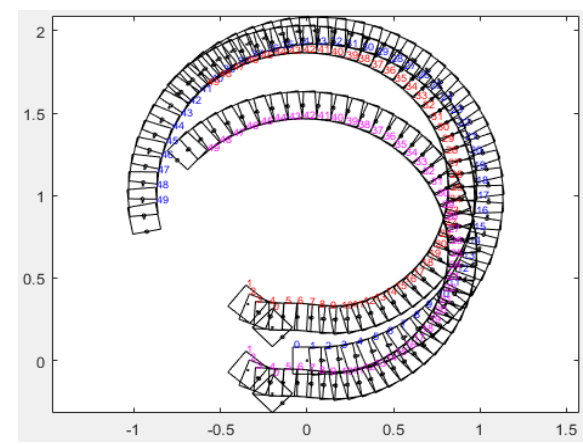

c

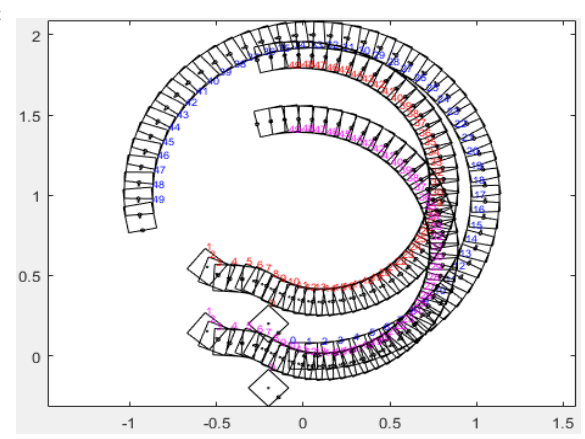

Şekil 6. (a)- (b) Liderin Takipçilerden İki Katı Hızla Başlaması; (c) Takipçilerle Liderin Başlangıç Hızları Arasında Çok Fark Olmasi Durumu

Başlangıçta, lider takipçilerin hızının iki katı hızla başladığında; eğer bu hız çok fazla ise, takipçi lideri izlemekte zorlanıyor. Şekil 6 hem a hem de b'de lider takipçilerin iki katı hızla başlıyor. Fakat a'da liderin hızı 0.2 birim/s iken b'de liderin hızı 0.1 birim/s'dir. Şekil 
6 c'deki gibi eğer takipçi ve liderler arasında çok hız farkı varsa (negatif yönler dahil) takipçilerin ikinci adımda ani konum değiştirdiğgi gözlemlenmiştir.

\subsection{Başlangıç Açısal Hızları ( $\omega$ )}

Bu bölümde robotların harekete çeşitli açısal hızlarla başlayıp devamında verdiği tepkiler gözlemlenmiştir.

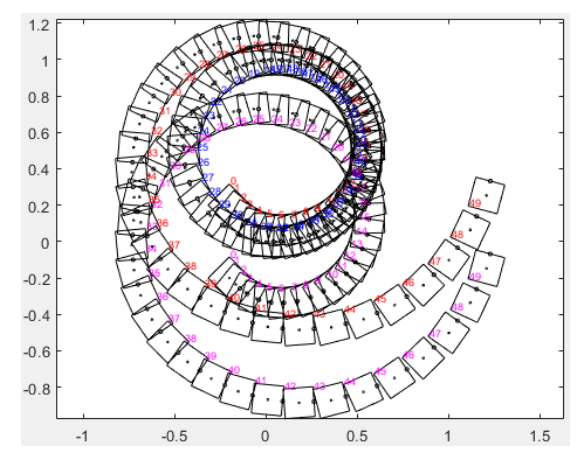

b

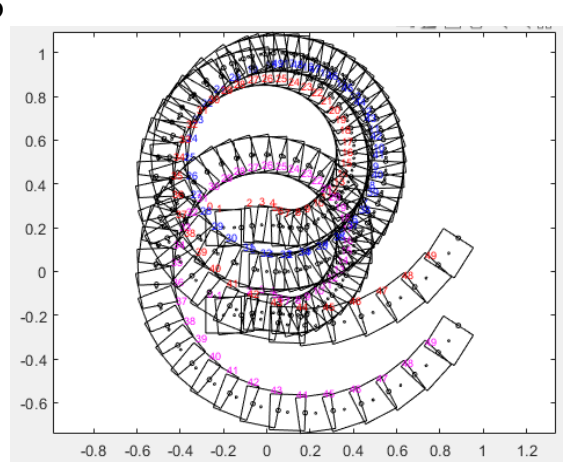

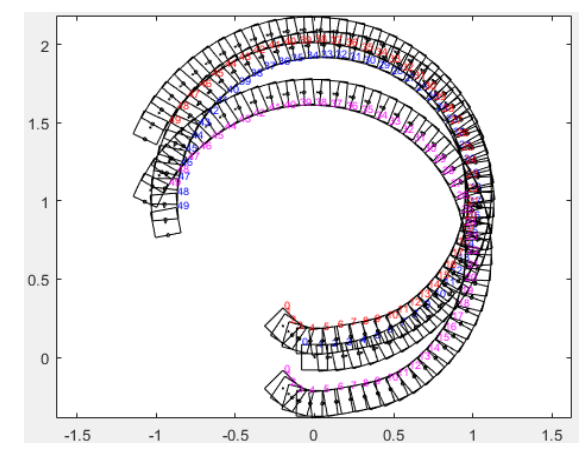

Şekil 7. (a) Takipçilerin Açısal Hızlarının Liderinkinden Fazla Olması; (b) Üçünün de Başlangıç Açısal Hızlarının Aynı Olması; (c) Takipçilerin Liderden Daha Büyük Açısal Hıza Sahip Olması

Takipçilerin başlangıçtaki açısal hızları liderinkinden fazla olursa, takibin sonlarına doğru takipçilerin rotadan uzaklaştığı gözlemlendi. Şekil 7a'da liderin açısal hızı $0.2 \mathrm{rad} / \mathrm{s}$ ve takipçilerin başlangıç açısal hızı ise $0.1 \mathrm{rad} / \mathrm{s}$ seçildiğindeki simülasyon görülebilir. Benzer durum Şekil 7b'de görülmüştür. Burada hepsinin başlangıç açısal hızları $0.1 \mathrm{rad} / \mathrm{s}$ 'dir. Takipçilerin liderden daha büyük açısal hıza sahip olması durumunda Şekil 7c'de takibin daha başarılı olduğu gözlemlenmiştir. Burada liderin açısal hızı $0.1 \mathrm{rad} / \mathrm{s}$ ve takipçilerin başlangıç açısal hızları ise $0.2 \mathrm{rad} / \mathrm{s}$ seçilmiştir.

\subsection{Başlangıç Açıları $(\theta)$}

Bu bölümde robotların harekete çeşitli $\theta$ açılarıyla başlayıp devamında verdiği tepkiler gözlemlenmiştir. Bu $\theta$ açısının konumu Şekil 2'de görülebilir.

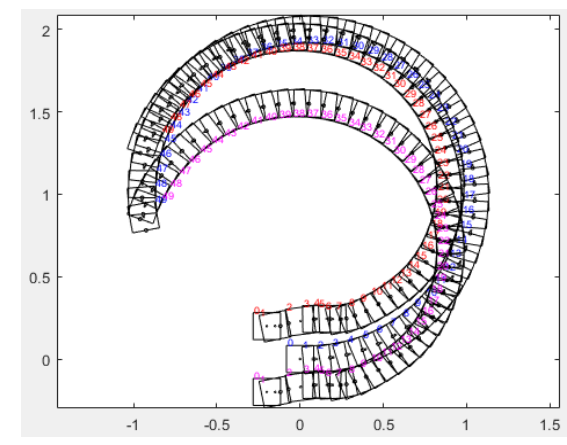

b

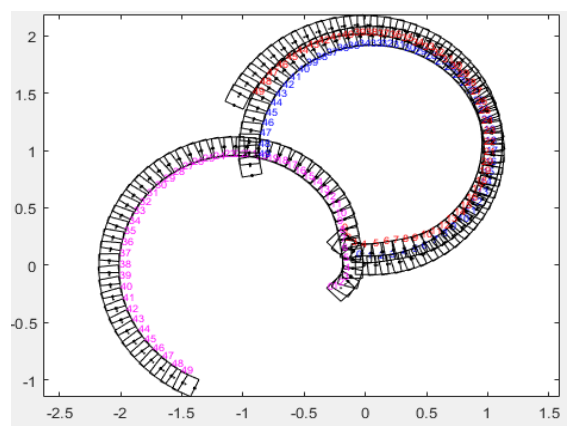

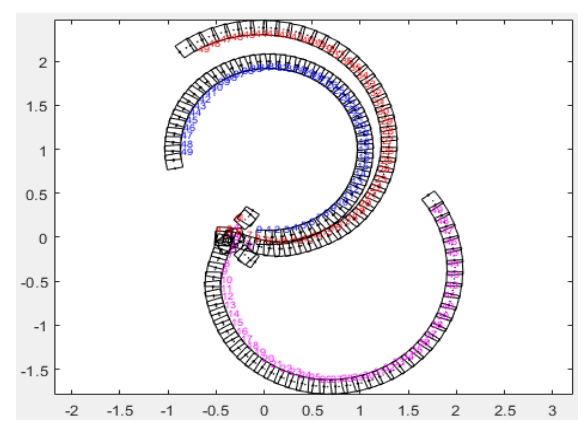

d

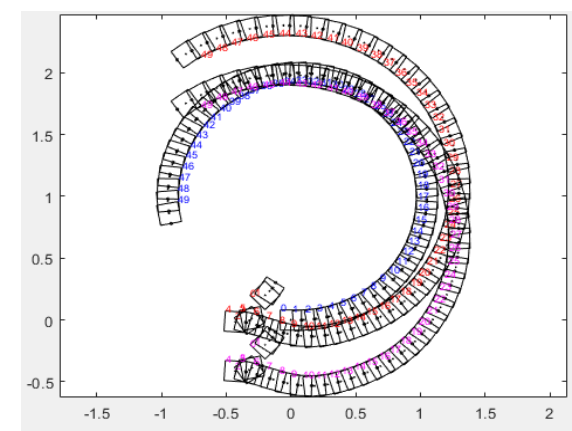

$\mathrm{e}$

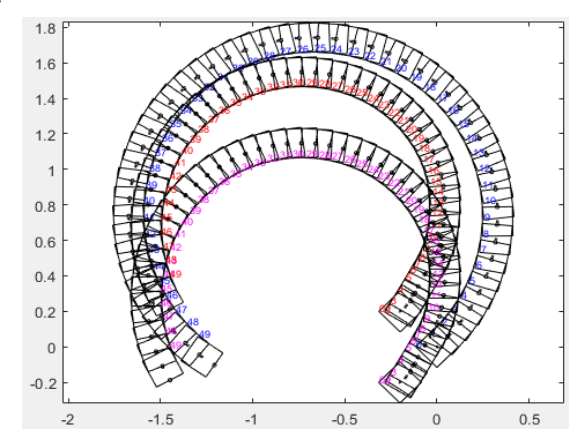

Şekil 8. (a) Bütün Başlangıç Açılarının Sıfır Olması; (b) Üçüncü Robotun Harekete Diğerlerine Yönelerek Başlaması; (c) Takipçilerin Harekete Birbirlerine Yönelerek Başlamış Olması; (d) İki Takipçinin Aynı Pozitif Yönde Harekete Başlaması; (e) Üçünün de Aynı Pozitif Yönde Harekete Başlaması 
Bütün robotların başlangıçtaki açıları sıfır olduğunda Şekil 8a'da çarpışma gözlemlenmiştir. 3. Robotun diğerlerine yönelerek harekete başlaması durumunda takip yapamamıştır. Şekil 8b'de liderin başlangıç açısı $0 \mathrm{rad}, 2$. Robotun $-\pi / 4 \mathrm{rad}, 3$. Robotun ise $\pi / 4 \mathrm{rad}$ seçilerek bu durum gözlemlenmiştir. Takipçilerin yüzleri birbirine dönük olarak harekete başladığında da 3 . Robot takip yapamamışıır. Şekil $8 \mathrm{c}$ 'de liderin başlangıç açısı $0 \mathrm{rad}, 2$. Robotun $\pi / 4 \mathrm{rad}, 3$. Robotun ise $-\pi / 4 \mathrm{rad}$ seçilerek bu durum gözlemlenmiştir. İki takipçi aynı pozitif yönde harekete başladıklarında, takipçiler başta biraz zorlanarak izleme yapmışlardır. Şekil 8d'de liderin başlangıç açısı 0 rad, 2. Robotun $\pi / 4 \mathrm{rad}, 3$. Robotun ise $\pi / 4$ rad seçilerek bu durum gözlemlenmiştir. Üç robotun aynı pozitif yönde harekete başlamaları durumunda çarpışma gerçekleşmiştir. Şekil 8e'de üçünün de başlangıç açıları $\pi / 4$ rad seçilerek bu durum gözlemlenmiştir.

\section{5 İstenilen Mesafeler (112d, 113d, 123d)}

$\mathrm{Bu}$ bölümde robotların hareketi boyunca birbirlerine göre olmasının istenildiği mesafeler çeşitli değerler için uygulanmıştır ve robotların hareketleri gözlemlenmiştir.

a

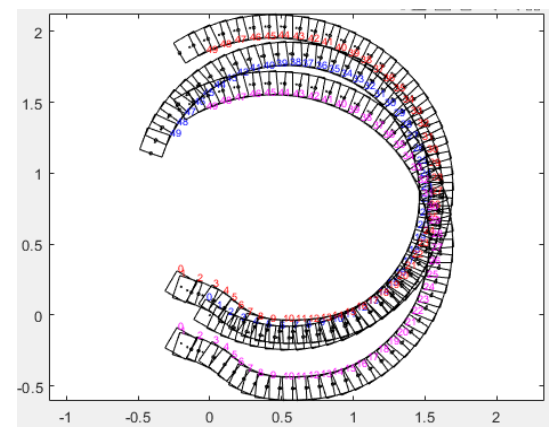

d

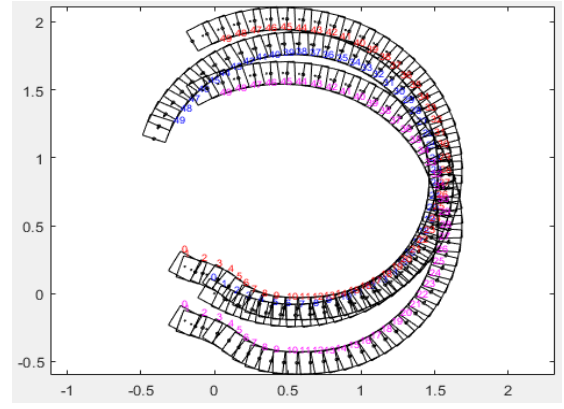

b

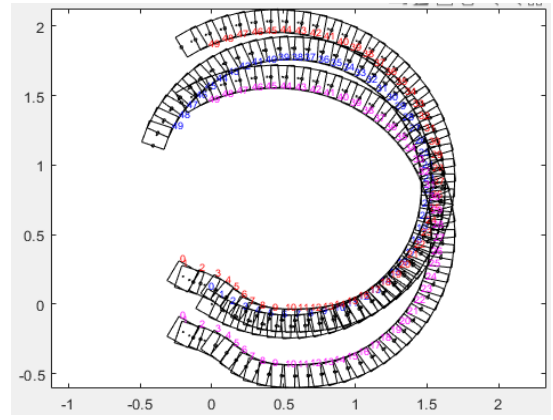

$\mathrm{e}$

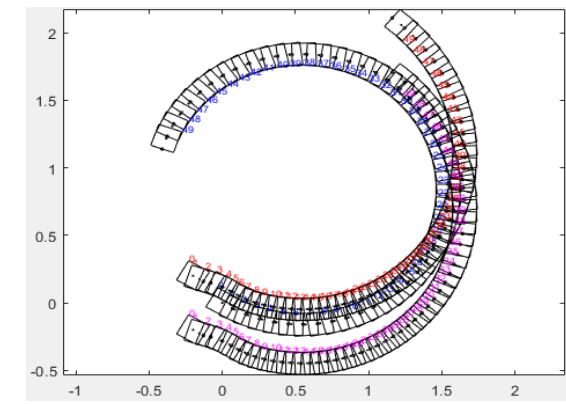

$\mathrm{c}$

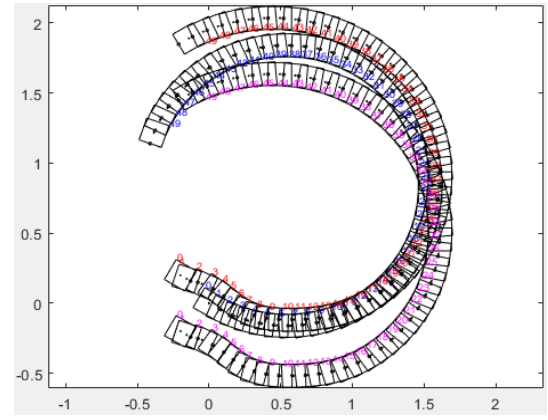

$\mathrm{f}$

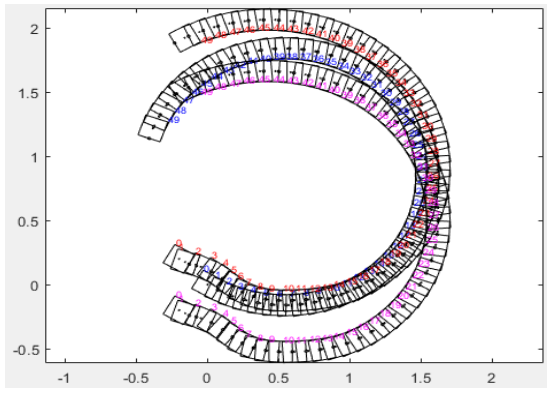

Şekil 9. İstenilen Mesafelerin Değiştirilmesi Durumunda Robotların İzlediği Yollar

İstenen mesafelerin -5 birim'den 50 birim'e kadar değiştirildiğinde izlemenin bozulmadığı, sadece çok fazla seçilmesi durumunda takipçilerin biraz daha yavaş hareket ettiği gözlemlendi. Şekil 9a'da 0.3 birim, 9 b'de 0.1 birim, 9c'de 0 birim, 9 d'de 5 birim, 9 e'de 50 birim, 9f'de -5 birim olarak seçilmişsir.

\section{6 İstenilen $\Psi$ Açıları (Robotların Birbirlerine Göre Yönelimleri)}

$\mathrm{Bu}$ bölümde robotların hareketi boyunca birbirlerine göre olmasının istenildiği mesafeler çeşitli değerler için uygulanmıştır ve robotların hareketlerinde herhangi bir değişikliğin olmadığı gözlemlenmiştir.

\section{Bulgular}

Çeşitli başlangıç değerleri ile yapılan, $l-\Psi$ ve $l-l$ kontrol kurallarının uygulandığ ü u̧ robotun olduğu simülasyonlarda, takibin bazı başlangıç değerlerinde daha iyi yapıldığı, bazı başlangıç değerlerinde de takibin iyi yapılamadığı ya da hiç yapılmadığı gözlemlenmiştir. Formasyon kontrolünde:

- takipçilerin liderden daha düşük hızda başladığı,

- $\quad$ liderin en önde olduğu,

- 2. Robotun liderin arkasında 3. Robotun da hem liderin hem de 2. Robotun arkasında harekete başladığı,

- takipçilerin liderinkinden daha büyük açısal hıza sahip olduğu,

- $\quad$ üç robotun da aynı negatif yönde harekete başladı̆̆ı durumlarda

takibin çok iyi yapıldığı gözlemlenmiştir. Takibin en iyi yapıldığı optimal başlangıç değerleri Tablo 1'de ve bu değerlerle takip de Şekil 10 'da verilmiştir. 
Tablo 1. Optimal Başlangıç Değerleri

\begin{tabular}{lll}
\hline $\begin{array}{l}\text { Değişken } \\
\text { İsmi }\end{array}$ & $\begin{array}{l}\text { Başlangıç } \\
\text { Değeri }\end{array}$ & Birim \\
\hline $\mathrm{x}_{2}(0)$ & -0.2 & $\mathrm{birim}$ \\
$\mathrm{y}_{2}(0)$ & 0.2 & $\mathrm{birim}$ \\
$\mathrm{x}_{3}(0)$ & -0.2 & $\mathrm{birim}$ \\
$\mathrm{y}_{3}(0)$ & -0.2 & $\mathrm{birim}$ \\
$\mathrm{v}_{1}$ & 0.1 & $\mathrm{birim} / \mathrm{s}$ \\
$\mathrm{v}_{2}(0)$ & 0.05 & $\mathrm{birim} / \mathrm{s}$ \\
$\mathrm{v}_{3}(0)$ & 0.05 & $\mathrm{birim} / \mathrm{s}$ \\
$\omega_{1}$ & 0.1 & $\mathrm{rad} / \mathrm{s}$ \\
$\omega_{2}(0)$ & 0.2 & $\mathrm{rad} / \mathrm{s}$ \\
$\omega_{3}(0)$ & 0.2 & $\mathrm{rad} / \mathrm{s}$ \\
$\Theta_{1}(0)$ & $-\pi / 6$ & $\mathrm{rad} / \mathrm{s}$ \\
$\Theta_{2}(0)$ & $-\pi / 6$ & $\mathrm{rad} / \mathrm{s}$ \\
$\Theta_{3}(0)$ & $-\pi / 6$ & $\mathrm{rad} / \mathrm{s}$ \\
$l_{12}^{d}$ & 0.5 & $\mathrm{birim}$ \\
$l_{13}^{d}$ & 0.5 & $\mathrm{birim}$ \\
$l_{23}^{d}$ & 0.5 & $\mathrm{birim}$ \\
$\Psi_{12}^{d}$ & $-\pi / 4$ & $\mathrm{rad} / \mathrm{s}$ \\
$\Psi_{13}^{d}$ & $-\pi / 4$ & $\mathrm{rad} / \mathrm{s}$ \\
& &
\end{tabular}

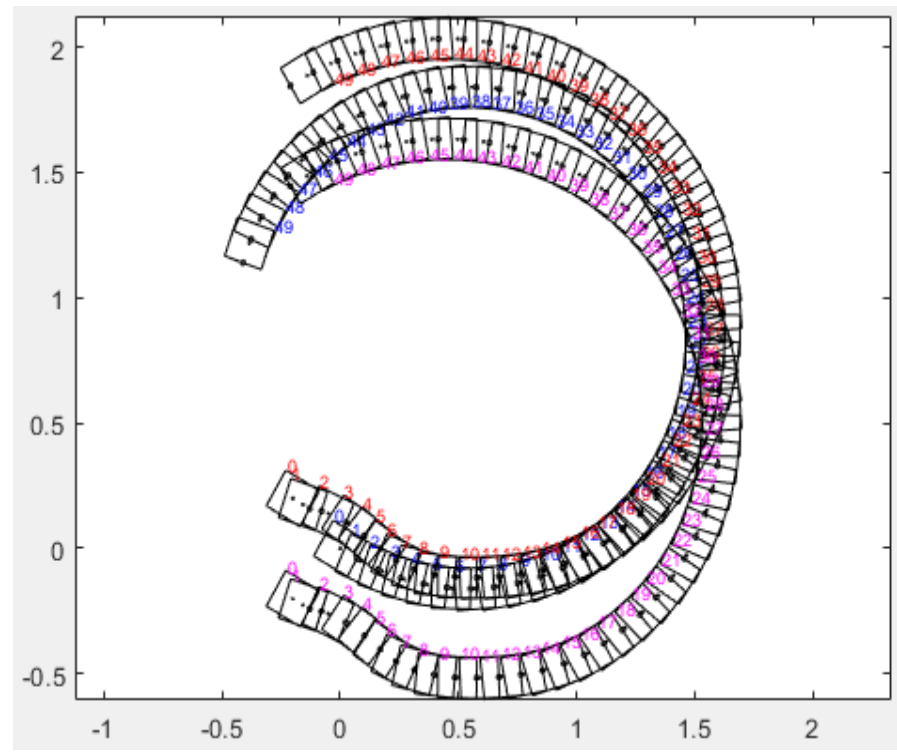

Şekil 10. Optimal Başlangıç Değerleri İle Robotların İzlediği Yollar 


\section{Sonuç}

(Desai vd., 1998, Desai vd., 2001) çalışmasında, holonomik olmayan mobil robotlara $l-l$ ve $l-\Psi$ kontrol Tekniği uygulandığında, çarpışmadan kaçınmak için Şekil 2'de gösterilen parametrelerden $l_{12}, l_{13}$ ve $l_{23}>2 d$ şartının sağlanması gerektiğini söylemişlerdir. Bunun haricinde (Desai vd., 1998, Desai vd., 2001) çalışmalarında formasyon ile ilgili formasyon geometrisi veya formasyon başlangıç koşulları hakkında herhangi bir kısıt belirtilmemiştir. Bu makalede, bir lider ve iki takipçi robot için, çeşitli başlangıç koşullarında ilgili formasyon kontrolü simülasyonları gerçekleştirilmiştir. Robotların hareketlerine başlamadan önce, bulundukları pozisyon, birbirlerine göre yönelimler, robotların kendi açıları, birbirlerine göre konumları, başlangıçtaki açısal ve çizgisel hızları çeşitli değerler için denenmiştir. Bu başlangıç parametrelerinin bazı değerlerinde kontrolün ve izlemenin yapılmadığı ve takipçilerin takipten saptandığı gözlemlenmiştir. $\mathrm{Bu}$ değerlerin hangi aralıklarda olduğu çalışmada verilmiştir. Formasyon geometrisi ve formasyon başlangıç koşullarının, (Desai vd., 1998, Desai vd., 2001)'de önerilen $l-l$ ve $l-\Psi$ kontrol tekniğinin başarılı bir şekilde çalışıp çalışmamasını doğrudan etkilediği gösterilmiştir.

\section{Referanslar}

Desai, J. P., Ostrowski, J., \& Kumar, V. (1998). Controlling formations of multiple mobile robots. Proceedings. 1998 IEEE International Conference on Robotics and Automation (Cat. No.98CH36146), 4, $2864-2869$ c.4. https://doi.org/10.1109/ROBOT.1998.680621

Desai, J. P., Ostrowski, J. P., \& Kumar, V. (2001). Modeling and control of formations of nonholonomic mobile robots. IEEE Transactions on Robotics and Automation, 17(6), 905-908. https://doi.org/10.1109/70.976023

Edwards, D. B., Bean, T. A., Odell, D. L., \& Anderson, M. J. (2004). A leader-follower algorithm for multiple AUV formations. 2004 IEEE/OES Autonomous Underwater Vehicles (IEEE Cat. No.04CH37578), 40-46. https://doi.org/10.1109/AUV.2004.1431191

Eren, T, Whiteley, W., Anderson, B. D. O., Morse, A. S., \& Belhumeur, P. N. (2005). Information structures to secure control of rigid formations with leader-follower architecture. Proceedings of the 2005, American Control Conference, 2005., $2966-2971$ c. 4. https://doi.org/10.1109/ACC.2005.1470425

Eren, Tolga. (2012). Formation shape control based on bearing rigidity. International Journal of Control, 85(9), 1361-1379. https://doi.org/10.1080/00207179.2012.685183

Fierro, R., Belta, C., Desai, J. P., \& Kumar, V. (2001). On controlling aircraft formations. Proceedings of the 40th IEEE Conference on Decision and Control (Cat. No.01CH37228), 2, 1065-1070 c.2. https://doi.org/10.1109/CDC.2001.981026

Flores-Resendiz, J. F., \& Aranda-Bricaire, E. (2020). A General Solution to the Formation Control Problem Without Collisions for First-Order Multi-Agent Systems. Robotica, 38(6), 1123-1137. https://doi.org/10.1017/S0263574719001280

Giulietti, F., Pollini, L., \& Innocenti, M. (2000). Autonomous formation flight. IEEE Control Systems Magazine, 20(6), 34-44. https://doi.org/10.1109/37.887447

Gosiewski, Z., \& Ambroziak, L. (2012). Formation Flight Control Scheme for Unmanned Aerial Vehicles. Içinde K. Kozłowski (Ed.), Robot Motion and Control 2011 (ss. 331-340). Springer London.

Hirzinger, G., Brunner, B., Dietrich, J., \& Heindl, J. (1994). ROTEX-the first remotely controlled robot in space. Proceedings of the 1994 IEEE International Conference on Robotics and Automation, 2604-2611 c.3. https://doi.org/10.1109/ROBOT.1994.351121

Hua, Y., Dong, X., Hu, G., Li, Q., \& Ren, Z. (2019). Distributed Time-Varying Output Formation Tracking for Heterogeneous Linear Multiagent Systems With a Nonautonomous Leader of Unknown Input. IEEE Transactions on Automatic Control, 64(10), 4292-4299. https://doi.org/10.1109/TAC.2019.2893978

Li, Z., Tang, Y., Huang, T., \& Kurths, J. (2019). Formation Control with Mismatched Orientation in Multi-Agent Systems. IEEE Transactions on Network Science and Engineering, 6(3), 314-325. https://doi.org/10.1109/TNSE.2018.2851199

Ma, H.-J., Yang, G.-H., \& Chen, T. (2021). Event-Triggered Optimal Dynamic Formation of Heterogeneous Affine Nonlinear Multiagent Systems. IEEE Transactions on Automatic Control, 66(2), 497-512. https://doi.org/10.1109/TAC.2020.2983108

Meng, Y., Chen, Q., Chu, X., \& Rahmani, A. (2019). Maneuver Guidance and Formation Maintenance for Control of Leaderless SpaceRobot Teams. IEEE Transactions on Aerospace and Electronic Systems, 55(1), 289-302. https://doi.org/10.1109/TAES.2018.2850382

Skjetne, R., Moi, S., \& Fossen, T. I. (2002). Nonlinear formation control of marine craft. Proceedings of the 4lst IEEE Conference on Decision and Control, 2002., 2, 1699-1704 c.2. https://doi.org/10.1109/CDC.2002.1184765

Wang, D., \& Fu, M. (2019). Adaptive Formation Control for Waterjet USV With Input and Output Constraints Based on Bioinspired 
Neurodynamics. IEEE Access, 7, 165852-165861. https://doi.org/10.1109/ACCESS.2019.2953563

Wang, X., Ni, W., \& Wang, X. (2012). Leader-Following Formation of Switching Multirobot Systems via Internal Model. IEEE Transactions on Systems, Man, and Cybernetics, Part B (Cybernetics), 42(3), 817-826. https://doi.org/10.1109/TSMCB.2011.2178022

Wen, G., Chen, C. L. P., \& Liu, Y. (2018). Formation Control With Obstacle Avoidance for a Class of Stochastic Multiagent Systems. IEEE Transactions on Industrial Electronics, 65(7), 5847-5855. https://doi.org/10.1109/TIE.2017.2782229

Yang, X., \& Fan, X. (2019). Robust Formation Control for Uncertain Multiagent Systems With an Unknown Control Direction and Disturbances. IEEE Access, 7, 106439-106452. https://doi.org/10.1109/ACCESS.2019.2932234 